\title{
Simulator Based Training to Improve Tradeoffs Analysis and Decision Making in Lean Development Environment
}

\author{
Michal Iluz ${ }^{1}$ and Avraham Shtub \\ ${ }^{1}$ Rafael Advanced Defense Systems Ltd., Haifa, Israel 61532 \\ michali@rafael.co.il \\ ${ }^{2}$ Faculty of Industrial Engineering and Management, \\ Technion-Israel Institute of Technology, Haifa 32000, Israel \\ shtubaie.technion.ac.il
}

\begin{abstract}
Challenging timetables, extreme requirements and increasing needs and expectations of stakeholders requires a new approach to project management and system engineering. Lean project development (i.e. Agile) is an emerging, promising methodology adapted by leading project management and systems engineering communities. The tools and techniques that can support this new methodology are being developed and tested by universities and industry.

This article focuses on the use of Simulation Based Training (SBT) as a tool for training Systems Engineers and Project Managers in a Lean project environment.

The Simulation Based Training (SBT) performed in this study is based on the Project Team Builder (PTB) simulator, which is an innovative project management and system engineering simulator designed as both a training/ teaching tool and a decision support system for project teams.
\end{abstract}

Keywords: SBT, tradeoff analysis, decision making, lean development.

\section{Introduction}

Project teams face complex decisions on a daily basis. In order to meet or exceed stake holders' needs and expectations project teams must plan and replant their project to keep it on track. Their decisions are made in an uncertain, dynamic and constrained environment spanning a large variety of areas such as outsourcing decisions, design decisions, risk management decisions, resource related decisions, budgets and schedule related decisions etc. Teamwork is essential in this challenging environment and shared understanding of the project goals and constraints is the foundation of teamwork.

Since erroneous Decisions are often costly, organizations invest considerably in training project managers and project teams and in decision support systems. 
The main focus of this article is on the following questions:

Q1: Does Simulation Based Training yield clearer insights regarding project tradeoffs?

Q2: Does Simulation Based Training improve decision making?

Specifically, the following hypotheses will be tested in controlled experiments and field studies:

H1: Simulation Based Training improves tradeoff analysis.

$\mathrm{H} 2$ : Simulation Based Training improves decision making.

\subsection{Decision Making}

The process of decision making is of a cognitive nature. A prevalent model [1] lists the following four stages:

- Collecting relevant data as a baseline for making a decision.

- Assessing all possible alternatives.

- Contemplating the various alternatives - comparing the different possibilities by anticipating the advantages and disadvantages of each of them.

- Choosing the preferred alternative = making a decision and committing to its performance while taking its specific consequences into consideration.

This model is applicable to the process of decision making both by individuals and by groups. The quality of decision making can be measured in two ways: the quality of the process and the quality of the decision.

Process quality - may be assessed by examining the alternatives considered, the methodology used, the way different parties are involved etc.

Decision quality - may be assessed by the results stemming from the decisions, i.e., adherence to requirements, the efficiency of using resources, the actual cost, the level of stake holders' satisfaction, etc.

\subsection{Simulation Based Training (SBT)}

Simulators are an effective tool for learning, practice and development of appropriate skills for problem solving and they have obvious advantages over other learning methods [2].

In recent years the use of simulators for learning and for supporting the decision making process has become very popular in various fields such as medical sciences, sociology, the military and engineering i.e., supply chain management and quality control [3].

Much research deals with the use of simulators in the learning process. [4] have raised ten hypotheses regarding the advantages of using simulators over other learning methodologies:

1. A simulator provides the user with applicable tools from the learned theory to its practical aspects. 
2. Using a simulator accelerates skill acquisition and specialization, as well as shortens learning duration, due to the simulator's ability to contract time and space dimensions.

3. A simulator provides a more realistic environment, closer to the "real world" working environment.

4. A simulator is able to simplify complex realistic problems so that they correspond to the users' level of knowledge and experience.

5. A simulator encourages critical thinking. Engaging in practice while using a simulator enables the users to make "risk free" errors and even to receive these errors implications as outputs without causing any real damage.

6. A simulator enables the user to run extreme scenarios which are rarely practiced, yet still are important to experience.

7. Using a simulator is of relatively low cost as compared to other learning and training methodologies that are in use to help make professionals more effective.

8. Simulators are usually simple to learn and to operate.

9. Controlled learning - the simulator enables each user to advance according to their own pace.

10. The experience of learning - the simulator is based on a learning game which creates interest and pleasure for the user, who in turn maintains a higher learning motivation level than the level displayed in passive learning methodologies.

A host of project simulators have been developed for various purposes. Notable examples are: SimProject, Project Scheduling Game, Topsim, PEG (Project Execution Game), Simultrain and others. The Simulation Based Training (SBT) that will be performed in this study is based on the Project Team Builder (PTB) simulator.

\subsection{The Project Team Builder Simulator}

The Project Team Builder (PTB) is based on a simulation approach; the simulator can simulate one or more projects or case studies. Each case study is a project or a collection of projects performed under schedule, budget, and resource constraints, with a given set of requirements in a dynamic stochastic environment. A user-friendly case study generator facilitates the development of new case studies as required. The simulations are dynamic: the "real" situation changes over time while running the scenario. A random effect is introduced to simulate the uncertainty in the environment. The user can plan the activities of the project in several ways (modes). The various modes represent the technological or operational alternatives. The selections of modes affect the time, the cost and the performances of the simulated project. The simulator contains a model base with well-known models for scheduling, budgeting, resource management and monitoring, and control.

The PTB simulator is unique because it is designed as a teaching tool and as a decision support system for project managers and their teams. The user can develop and analyze scenarios for a range of real projects that should be analyzed (construction projects, R\&D projects, software development projects and infrastructure projects such as those in the chemical and energy industries). By separating the simulator engine 
from the scenario building module any real project can be developed into a scenario and used to train and/or to support decision making processes as explained next.

PTB contains widely used models of project management-e.g., Network and Gantt charts for project scheduling, cash flow charts for budget planning, resource load charts for resource planning, Monte Carlo simulation for risk management, and a monitoring and control module for tracking project performance.

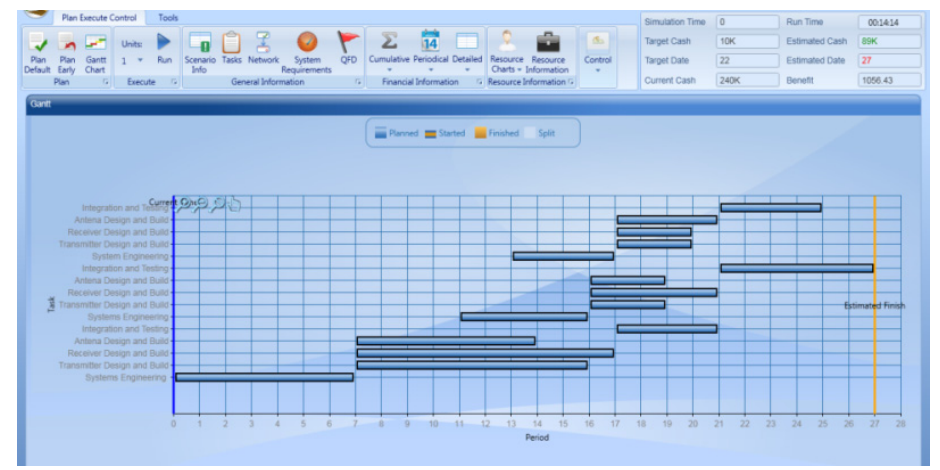

Fig. 1. Screen caption from PTB showing an example of a project Gantt chart

Trainee success in the PTB simulation is determined by the quality of their decisions and the time required running the scenario. The quality of decisions is measured by the compliance with the required performance of the developed system, project duration and by the total project cost at the completion of the simulation.

The simulator measures the runtime of each scenario from start to finish.

We hypothesize that use of the PTB simulator for training project managers and system engineers improves the decision making process so that the results obtained at the end of the project are better in terms of cost, performance and duration.

The paper is organized as follows: The next section presents typical decisions in the area of project management. Next we present the research questions and hypotheses.

The following chapter describes the research methodology. Finally, the results of the experiments are discussed and conclusions are presented.

\section{Methods}

Two experiments were performed. The first was performed on individual participants whereas the second was performed on project teams, as described above.

\subsection{Scenario Description}

For this research, real project-based scenarios were developed. For example, the "Transceiver" scenario (see Fig. 2) is based on a real-life project of an airborne communications system. 


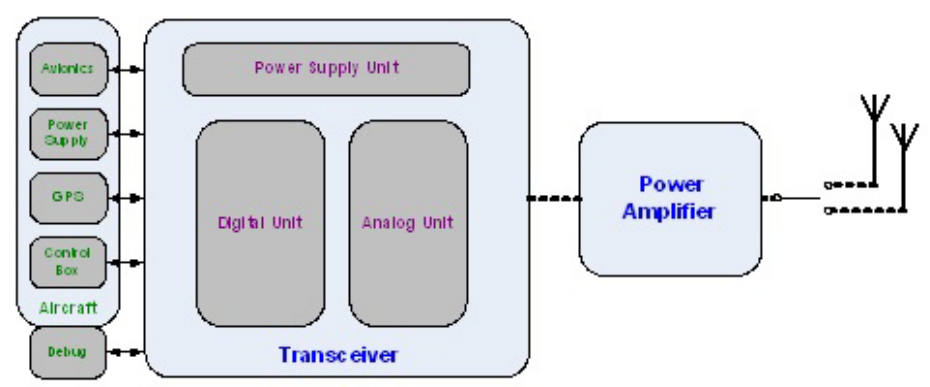

Fig. 2. "Transceiver" system block diagram

The simulated scenario reflects two typical design alternatives:

1. Improvement of receiver reception sensitivity ("listening more carefully").

2. Transmission power increase ("shouting louder").

\subsection{Activities and Modes in the Scenario}

Table 1 presents an example of the possible modes (viz. performance) alternatives for each activity in the scenario.

Table 1. Activities and Modes in the Scenario

\begin{tabular}{|c|c|c|c|c|}
\hline $\begin{array}{l}\text { Activity } \\
\text { Number }\end{array}$ & $\begin{array}{l}\text { Activity } \\
\text { Name }\end{array}$ & $\begin{array}{l}\text { Reception } \\
\text { Improvement } \\
\text { Alternative }\end{array}$ & $\begin{array}{c}\text { Transmission } \\
\text { Power } \\
\text { Increase } \\
\text { Alternative }\end{array}$ & $\begin{array}{l}\text { Influence on } \\
\text { System } \\
\text { Performance - } \\
\text { Schedule/Cost }\end{array}$ \\
\hline 1 & $\begin{array}{l}\text { Modem card } \\
\text { developmen } \\
\mathrm{t}\end{array}$ & $\begin{array}{l}\text { Highly } \\
\text { complex }\end{array}$ & Standard & $\begin{array}{l}\text { More expensive and } \\
\text { longer schedule }\end{array}$ \\
\hline 2 & $\begin{array}{l}\text { Power } \\
\text { supply }\end{array}$ & $\begin{array}{l}\text { Standard - off } \\
\text { shelf }\end{array}$ & $\begin{array}{l}\text { Assigned power } \\
\text { supply }\end{array}$ & $\begin{array}{l}\text { Investing in design, } \\
\text { schedule. } \\
\text { Designated supplier } \\
\text { provides higher } \\
\text { performance }\end{array}$ \\
\hline 3 & $\begin{array}{l}\text { Power } \\
\text { amplifier }\end{array}$ & $\begin{array}{l}\text { Standard } \\
\text { Reuse }\end{array}$ & Redevelopment & $\begin{array}{l}\text { More expensive and } \\
\text { longer schedule }\end{array}$ \\
\hline
\end{tabular}

\subsection{Measurements}

The measurements performed in the experiment are:

1. System performance requirements - a weighted score given at the end of the simulator run. This score is termed "benefit".

2. Cost at project completion. 
3. Project duration.

4. Simulator run-time.

These measurements are the result of the decisions made by the trainee. Additional information was collected by questionnaires.

\subsection{Experiment Description}

\subsubsection{Experiment \#1: Individual Participants}

Three groups participated in this experiment:

- A group of 16 very experienced project managers with experience of over 5 years.

- A group of 17 experienced project managers with fewer than 5 years of experience.

- 18 graduate students

The essence of the experiment is to let the trainees "manage" the project themselves. Their goal is to optimize the ratio between system performance and costs (cost benefit analysis). Upon completion of the simulation, each participant was handed a questionnaire focused on tradeoffs analysis and decision making.

2.4.2 Experiment \#2: Project teams

Nineteen project teams participated in this experiment with a sample size (i.e., the number of participants) of $\mathrm{N}=57$.

A crossover (PTB/MSP) experiment was designed to test whether SBT improves tradeoff analysis and decision making.

Participants were randomly divided into teams and roles, each including a Project Manager, a Systems Engineer, and a Quality Assurance Engineer. The teams' target was to optimize the ratio between system performance and costs.

Upon completion of the PTB/MSP project plans and runs, participants were requested to record the plan results: duration, cost, performance, as well as to fill out a questionnaire focused on tradeoffs analysis and decision making.

\subsection{Data Analysis}

The data were analyzed using two statistical procedures: the Chi-square test and the Analysis of Variance (ANOVA). ANOVA is aimed at testing the differences between the means of more than two samples, and is based on the partitioning of the variance in the data into different sources.

The results of the analysis are reported below in the following format: Chi-square $=\mathrm{XX} ; \mathrm{df}=\mathrm{XX}, \mathrm{P}<\mathrm{XX}$. The value of the statistic in the test was performed, Chi-square is presented first. This is followed by the number of Degrees of Freedom (df) that were used in the test. Finally, the significance is indicated by P, which is the probability of making an error in claiming that the difference is significant. Any probability less than $5 \%$ is interpreted in Behavioral Science as a significant difference. 


\section{$3 \quad$ Results}

There are three clusters of compliance with performance: low (benefit under 20,000), moderate (benefit between 20,000 and 80,000) and high (benefit over 80,000).

1. The effect on tradeoffs analysis is shown by a significant correlation between performance and cost as shown in Fig. 3. (Chi Square $=5.99, \mathrm{df}=2, \mathrm{P}<0.05)$. The better the performance, the higher the cost.

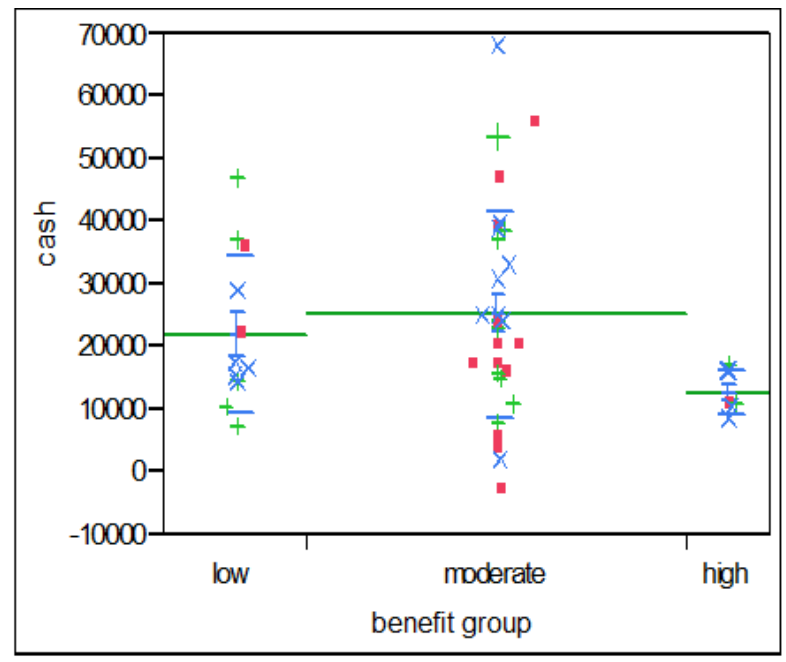

Fig. 3. One-way analysis of cash by benefit group

2. The relationship between the notion that the tool supports decision making and the will to integrate it before or during project life: There is a significant correlation $(\mathrm{F}=3.5, \mathrm{df}=4, \mathrm{P}<0.05)$ between perceiving the simulator as a supporting tool for making decisions and the will to integrate it as a tool for making decisions before or during project performance.

3. The influence of the tool used on the tradeoff analysis was determined by statistically analyzing the questionnaire answers. A Signed-Rank test was performed on two independent samples. This test resembles a single t-test. The differences (PTB-MSP) between the answer given following use of the PTB and the answer given following use of MSP were analyzed. In case the mean value is positive and the $\mathrm{P}$ value $<0.05$ (indicating significant statistic), the result is in favor of PTB. In other cases, the average result was negative, but the $\mathrm{P}$ value was not significant $(>0.05)$. In these cases no conclusion could be drawn in favor of the MSP. An example of the analysis results is depicted in Table 2. 
Table 2. Difference analysis results summary on the question level. Significant results are indicated by yellow highlight

\begin{tabular}{|l|l|l|l|l|l|}
\hline $\begin{array}{l}\text { Question } \\
\text { number }\end{array}$ & Question description & $\begin{array}{l}\text { Average } \\
\text { difference } \\
\text { (PTB-MSP) }\end{array}$ & $\begin{array}{l}\text { Std Error } \\
\text { difference } \\
\text { (PTB- } \\
\text { MSP) }\end{array}$ & $\begin{array}{l}\text { P_Value } \\
\text { (2 sides) }\end{array}$ & $\begin{array}{l}\text { P_Value } \\
(1 \text { side })\end{array}$ \\
\hline $2(2 \mathrm{~A})$ & $\begin{array}{l}\text { How well do you } \\
\text { understand the project } \\
\text { work process? }\end{array}$ & 0.0023 & 0.0045 & 0.1213211 & 0.3508772 \\
\hline 3 & $\begin{array}{l}\text { How well do you } \\
\text { understand the } \\
\text { possible trade-offs } \\
\text { within the project? }\end{array}$ & 0.0359 & 0.0718 & 0.1301087 & 0.2280702 \\
\hline 4 & $\begin{array}{l}\text { How clear are the } \\
\text { decisions you are } \\
\text { required to make? }\end{array}$ & 0.0165 & 0.0330 & 0.1270308 & 0.2807018 \\
\hline 6 & $\begin{array}{l}\text { How well do you } \\
\text { believe the other team } \\
\text { members understand } \\
\text { the relationship } \\
\text { between time and } \\
\text { performance within } \\
\text { the project? }\end{array}$ & 0.2982456 & 0.1250687 & 0.0204 & 0.0102 \\
\hline
\end{tabular}

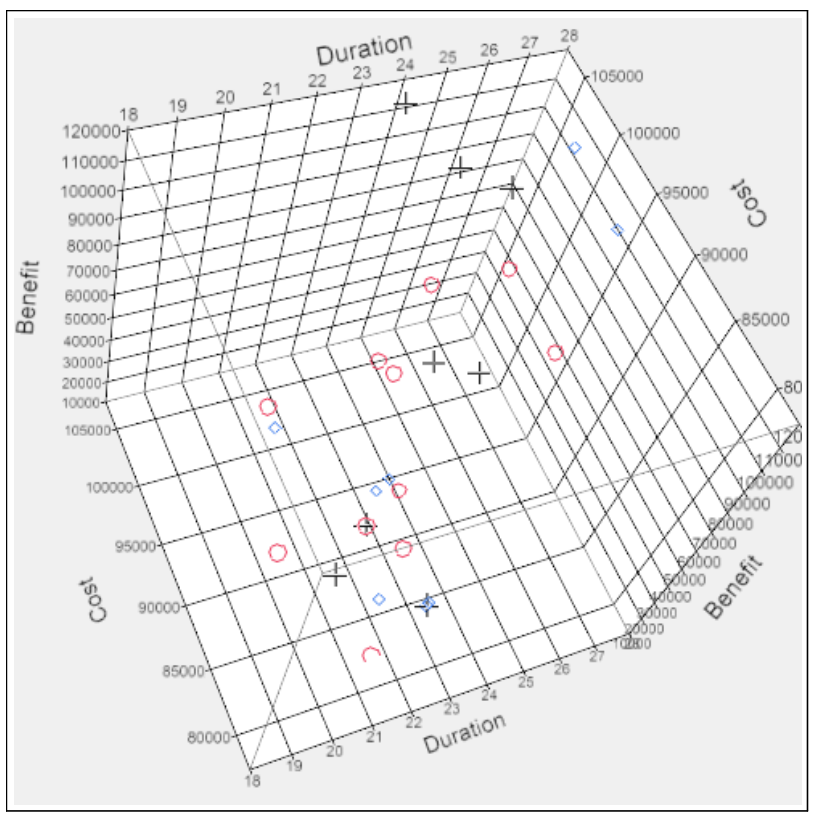

Fig. 4. Team results upon completion of simulation runs with aspects of timing, cost and performance, as compared to the efficiency frontier 
Ten out of 16 questions (over 60\%) yielded statistical significance with regard to using SBT. However, even when there is no significance, no advantage is seen in favor of the MSP. Even when the observed difference is negative, no significance is detected.

The conclusion is, therefore, that SBT improves tradeoffs analysis and decision making.

Fig. 4 simultaneously compares three dimensions: cost, performance and duration. The results are seen to be clustered in three performance levels: Low, Moderate, and High Benefits. Result analysis shows that in the High performance level teams that opened with SBT tend to achieve higher performance than teams that opened with the MSP tool. The conclusion is, therefore, that SBT contributes to improved project outcomes.

Legend:

+ Efficiency Frontier

o Sample 1

$\diamond$ Sample 2

\section{Discussion and Conclusions}

- The results show that as performance increases, cost increases. These parameters reflect an existing and expected tradeoff.

- The performance requirements for this project could have been implemented in a number of ways and each way provides some compliance with performance requirements. In the real project, the customer is demanding, familiar with the technology and its limits, so that the actual implementation was taken to its technology limit. We had only 6 participants who finished with high end performances, 3 of them were system engineering Master's students, 2 experienced project managers and only one was a very experienced project manager.

- The participants who were interested in providing a fully compliant system did actually achieve this goal in the simulation. However, the price paid for performance improvement (full compliance vs. partial compliance) was higher cost. In other words, project managers who insist on completing the project with full compliance with performance requirements (for various reasons) should take into consideration that the project cost will be higher compared to the cost they may reach with nearly full performance compliance.

- The results of this research demonstrate that SBT improves tradeoff analysis and decision making. SBT can be used effectively to build project teams in a Lean environment. Teams can be trained using SBT with a focus on the real project assigned to the team. By simulating a scenario based on the real project, the team can learn how to integrate the different aspects of project management, and-more importantly - can learn to work and solve problems together. As a result, the project is expected to be managed more efficiently. 


\section{References}

1. McMahon, M.: Career Coach: Decision Making. Pulse, United Kingdom (2007)

2. Kumar, A., Labib, A.W.: Applying Quality Function Deployment for the Design of a Nextgeneration Manufacturing Simulation Game. Int. J. Eng. Educ. 20(5), 787-800 (2004)

3. Shtub, A., Parush, A., Hewett, T.: The Use of Simulation in Learning and Teaching. International Journal of Engineering Education 25(2), 206-209 (2009)

4. Salas, E., Wildman, J.L., Piccolo, R.F.: Using Simulation-based Training to Enhance Management Education. The Academy of Management Learning and Education (AMLE) 8(4), 559-573 (2009) 